\title{
Knowledge and Performance of Mothers Having Children with Cancer Undergoing Chemotherapy
}

\section{${ }^{1}$ El Shaima Gamal Hasan; ${ }^{2}$ Soheir Abd-Rabou Mohamed; ${ }^{3}$ Sanaa Mahmoud Ahmed; ${ }^{4}$ Khalid Fathy Riad 5Aml Sayed Ali}

(1) Master degree in Pediatric Nursing Faculty of Nursing, Minia University

(2) Professor of Pediatric Nursing, Faculty of Nursing - Cairo University

(3) Assistant Professor of Pediatric Nursing Faculty of Nursing - Minia University

(4) Assistant Professor of Pediatric Oncology South Egypt Cancer Institute - Assiut University

(5) Assistant Professor of Pediatric Nursing Faculty of Nursing - Minia University

\begin{abstract}
Background: Cancer is a leading cause of death for children worldwide. More than $80 \%$ of children with cancer are cured in high-income countries, but only $20 \%$ are cured in many low-income countries. Aim: To assess the knowledge and performance of mothers having children with cancer undergoing chemotherapy. Research design: Descriptive research design was used in the current study. Sample: A purposive sample of 35 mothers having children with cancer and undergoing chemotherapy participated in the study. Setting: The current study was conducted at the pediatric unit at Minia Oncology Center. Tools: Tool (I): Structured Interview Sheet: covered the personal data of the mothers and the characteristics of the child; Tool (II): mothers Knowledge Assessment Sheet and Tool (III): mothers Performance Assessment Sheet. Results: There was lacking knowledge and performance of mothers having children with cancer undergoing chemotherapy. There were no statistically significant relationships between the total mean scores of mothers' knowledge and total mothers' practice regarding childhood cancer and chemotherapy as well as their personal data as age, level of education, their children's age, gender and the child's rank in the family $(p=>0.05)$. Conclusion: The study concluded that the overall level of mothers' knowledge and performance was unsatisfactory. Personal variables have no impact on the knowledge and performance of the mothers. Recommendation: The study recommended that developing periodic educational programs and instructions to mothers having children with cancer undergoing chemotherapy would improve their knowledge and performance regarding childhood cancer and chemotherapy.
\end{abstract}

Keywords: Childhood Cancer, Chemotherapy, Mothers, knowledge, performance

\begin{abstract}
Introduction
Childhood cancer is a significant public health problem worldwide and is the second leading cause of death after accidents in children ages one to fourteen. Approximately 1,190 children under the age of fifteen are predicted to die from cancer in 2020. Around 11,050 children in the United States under fifteen will be detected with cancer in 2020. Childhood cancer rates have been rising to some extent for the past few decades. Because of significant treatment advances in recent decades, $84 \%$ of children with cancer now survive five years or more. Overall, this is a considerable increase since the mid-1970s, when the 5-year survival rate was about 58\% (American Cancer Society, 2020).
\end{abstract}

More than eighty percent of children with cancer are preserved in high-income countries, but in many low-income and middle-income countries (LMICs), only $20 \%$ are cured. The reasons for lesser survival rates in LMICs include an incapability to attain an accurate diagnosis, inaccessible therapy, abandonment of treatment, death from toxicity (side effects), and excess relapse, in part due to lack of access to essential medicines and technologies addressing each of these gaps expands survival and can be highly cost-effective (World Health Organization [WHO], 2018; Howard et al., 2018).

In the study of childhood cancer survivors and health outcomes over the last ten years in Children's Cancer Hospital 57357 Egypt (CCHE), to determine the variations in survival by demographic, cancer type. A total of 15,997 children with cancer were analyzed; $58 \%$ were males and $42 \%$ females. The highest percentage of the children $(48 \%)$ were in the youngest age group (0-4 years). Fifty-nine percent of the children had solid tumors, and $41 \%$ had hematologic malignancies. The most common cancers were leukemia, lymphoma, central

$P$ a g e $\mid 65$ nervous system (CNS) tumors, and neuroblastoma. The survival rate was calculated for 14,553 children, representing $92.2 \%$ of the full study population (Soliman, Elhaida, Oke, Eweida, \& Sidhom, 2019).

Recently, Attar, Zagade, and Shinde (2020) documented that childhood cancer is treated with different treatment methods commonly involving chemotherapy, radiotherapy, surgery, immune therapy, stem cell therapy, targeted cell therapy, hormonal therapy, and precision medicine. As reported by Marcdante and kliegman (2019); Singaraju, Palaian, Shankar, and Shrestha (2020), chemotherapy is used in almost all cases of cancer in children. Over $50 \%$ of the children with cancer undergoing chemotherapy develop adverse drug reactions (ADRs). Cancer chemotherapeutic agents kill cancerous and the normal rapidly dividing cells, including bone marrow cells, gastrointestinal epithelium, hair follicles, and other side effects. Their main ADRs are nausea and emesis, mucositis, constipation, diarrhea, hematological toxicities, cardiac toxicity, alopecia, gonadal toxicity, pulmonary toxicity, neurotoxicity, and nephrotoxicity. The severity of the adverse effects may vary from mild nausea to life-threatening neutropenia.

According to Tomlinson, Yuan, Cheng, and Hinds (2020), successful management of symptoms are imperatively attributable to the potential for harmful effects on the child's health and well-being. Children with cancer experience a myriad of symptoms, often occurring as symptom clusters. Symptoms for children with cancer and their families are burdensome, distressing, and often challenging to control. These symptoms result from the condition, its treatment, and associated procedures that can hinder the child's psychosocial and physical development and have adverse effects on the child's and family's quality of life. Experiencing frequent and 
severe symptoms is accompanied by a lower quality of life and may hinder multiple aspects of a child's development.

As documented by Ameringer, Macpherson, and Jibb (2020), Valizadeh et al. (2020), chemotherapy's side effects might keep a child from partaking in social interactions, such as playing or being with peers, that are key to facilitating psychosocial development. Symptoms as loss of appetite, nausea, and vomiting lead to inadequate nutritional intake, negatively affecting physical development. Detecting patients' needs is one of the primary steps of the nursing process to plan and implement nursing interventions and prevent late effects.

Leading health care organizations, including the WHO and the American Academy of Pediatrics (AAP), have endorsed that pediatric palliative care (PPC) ought to begin once a severe or life-threatening condition is diagnosed and continue no matter whether or not a child receives treatment aimed toward comfort or cure. Nurse clinicians and scientists were amongst the front runners within the field of pediatric palliative care within oncology. Several of the early nurse-led studies focused on the perspectives of mothers caring for their children with incurable cancer. Symptom management is a foundation of PPC, thus supporting the need for the early integration of PPC (Newman, Crane, Spruit, Alharrasi \& Bell, 2020).

Family education is an integral and crucial component of nursing care in pediatric oncology; it has recently been identified as a clinical and research priority within the pediatric oncology community. Expert consensus recommendations have been developed to usher the provision of education to families of newly diagnosed patients. Abundant the existing evidence for the provision of patient and family education in pediatric oncology is targeted to the time of initial cancer diagnosis. This underscores the overwhelming quantity of new information that is often provided in parallel with families' need to understand the diagnosis and treatment to provide safe care for the child within the home setting. It also highlights the significant emotional impact of the new cancer diagnosis upon the child and family (Haugen, Zupanec \&Landier, 2020).

\section{Significance of the study}

Cancer is a chief cause of death among children worldwide; it's a life-threatening condition and a significant public health problem for pediatric patients. Globally millions of children die yearly due to cancer. 1,735,350 newly diagnosed cases and 609,640 cancer deaths are projected to occur in the United States (Siegel, Miller \& Jemal, 2019).

The global cancer burden has doubled within the last thirty years of the twentieth century. It is estimated that this will double again between 2000 and 2020 and nearly triple by 2030 . The cancer incidence estimate was $113.1 / 100,000$ of the total population in 2012, and $114,98 / 100,000$ of the total population in 2013. Projections to 2050 estimate cancer incidence in Egypt to be $341.169 / 100,000$ of the total population (National Cancer Control Plan of Egypt 2016-2020). Kamel, Baraka, Khalid, and Ibrahim (2009) reported that according to the results of Egypt National Cancer Registry, Minia profile, the total number of malignancies reported during 2009, amongst children under the age of 15 years, was 258 cases; these cases represented $5.6 \%$ of all incident cancers (total of 4584 patients).
Hence, the current study was undertaken to assess mothers' knowledge and performance regarding the care of children having cancer and undergoing chemotherapy. Results of the current study may help in evaluation of the mothers' knowledge and performance regarding care of children having cancer. As well as providing guidance and recommendations that should be reflected in pediatric nursing education and practice.

\section{Aim of the study}

The current study aimed to assess the knowledge and performance of mothers having children with cancer undergoing chemotherapy.

\section{Research Questions}

The current study results answered the following research questions:

- What is the level of mothers' knowledge regarding the care of children having cancer and undergoing chemotherapy?

- What is the level of mothers' performance regarding the care of children having cancer and undergoing chemotherapy?

\section{Research design:}

A descriptive research design was utilized to achieve the aim of the current study. This design helps describe a situation or an event in exploring and knowing the level of mothers' knowledge and performance regarding the care of children having cancer and undergoing chemotherapy.

Subjects:

A purposive sample of 35 mothers having children with cancer and undergoing chemotherapy participated in the current study. According to the statistical equation in which the sample size ranged between $10 \%$ to $30 \%$ from the total population size, the entire pediatric population admitted to the pediatric oncology unit at Minia Oncology Center was 126 children in 2017.

\section{Inclusion criteria:}

- Mothers were having newly diagnosed children with cancer and free from chronic illness as diabetes or renal failure or other types of malignancies.

- Mothers were having children and undergoing chemotherapy for the first time.

- Mothers who agree to participate in the study regardless of their age or educational level.

- Mothers who have no other child with cancer or any cancer patient receiving chemotherapy.

Setting:

The current study was conducted at the pediatric oncology unit at Minia Oncology Center that is located in Minia city. It serves Minia governorate and affiliated with the Ministry of Health and Population.

\section{Data collection tools:}

The following data collection tools were utilized. The researcher developed the tools after reviewing the related literature. 
Tool (I): Structured Interview Sheet: It involved 16 questions and classified into two parts:

Part I: It contained 11 items that cover the personal data of the mothers as age, educational level, material status, place of residence, and the number of children in the family. It also comprised the characteristics of the children with cancer and undergoing chemotherapy such as age, gender, and rank within the family.

Part II: It is comprised of five questions covers the current medical history of the children as diagnosis and type of cancer, as well as the duration of illness, medications, and previous hospitalization.

Tool (II): Mothers; Knowledge Assessment Sheet: It involved 21 questions classified into two parts:

Part I: It involved 5 Multiple Choice Questions (MCQs) to assess the mothers' knowledge regarding cancer, including definition, causes, predisposing factors, signs and symptoms, and methods of management.

Part II: It contained 16 MCQs questions to assess mothers' knowledge regarding chemotherapy, including definition, types, uses, phases, side effects on bone marrow, skin, digestive and respiratory systems, precautions, and measures to reduce the side effects.

Tool (III): Mothers' Performance Assessment

Sheet:

It involved 17 MCQs questions to evaluate the mothers' performance regarding the care of their children with cancer, such as care of signs and symptoms, e.g., nausea, vomiting, pallor, fatigue, bone or joint pain, infection, and anorexia. Mothers' performance was assessed regarding chemotherapy sessions, such as dealing with chemotherapy's side effects, e.g., fever, bleeding tendencies, mucosal ulceration, pain, nausea, and vomiting.

Scoring system: for mothers' knowledge and performance, each correct/ complete response took two scores; the incomplete one took one score, and zero score was given for the wrong answer or the not known/ done. The total score was converted to $100 \%$ and then categorized as following: score ( $\geq 50 \%$ ) was considered satisfactory level; meanwhile, mothers' overall score (less than 50\%) was regarded as an unsatisfactory level of knowledge/ performance. The total mothers' knowledge score was 42, while 34 scores for the mother's total response related to their performance. .

\section{Validity and Reliability}

The content validity of the tools was performed by a jury of 5 experts in pediatric nursing and pediatric oncology. Tools were examined for content coverage, clarity, relevance, applicability, wording, length, format, and overall appearance. Based on experts' comments and recommendations, modifications were made. The internal consistency was measured to identify the extent to which the tools measure the same concept and correlate. Cronbach's alpha coefficient was used to assess the tools' internal consistency were $.0861 \&$ .910 , correspondingly.

\section{Ethical Considerations:}

Written approval obtained from the Research Ethics Committee of the Faculty of Nursing, Minia University; there was no risk for study subject during application of the current study, oral consent was taken from all mothers to participate in the study. The researcher explained the study's purpose and nature through direct personal communication before participating in the study. These data were confidential and were used for the research only. The study followed the common ethical consideration to participate in clinical research, and privacy was assured during data collection. Anonymity and privacy were assured through coding the data, and a mother has the right to refuse to participate in the study without any rationale. Children and their mothers were informed that participation in the study was voluntary; the researcher also informed the mothers about their rights to withdraw from the study without giving any reason and without any effect on their children's care.

\section{Data Collection Procedure:}

Primary approval was obtained from the Research Ethics Committee, Faculty of Nursing, Minia University. Official permission was obtained from the administrator of Minia Oncology Center and permission from the head of the pediatric oncology unit after explaining the study's aim and nature. After that, data collection started; the researcher went to Minia oncology center for two days per week.

Mothers were interviewed on individual bases to explain the nature and purpose of the study and obtain personal data about their children's characteristics and current medical history with cancer and undergoing chemotherapy (tool I). The interview took place in the inpatient rooms in the pediatric oncology unit at Minia Oncology Center. Mothers' knowledge and performance regarding their children's care with cancer and undergoing chemotherapy were assessed using (tools II, III). The duration of the interview was ranged from 25-30 minutes. Data collection was conducted over twelve months extending from January 2019 till December 2019.

\section{Pilot Study}

The pilot study was conducted on $10 \%$ (four mothers having children with cancer and undergoing chemotherapy) who met the inclusion criteria was done to ensure the feasibility, objectivity, applicability, clarity, adequacy, content validity, and internal consistency of the study tools and to determine possible problems in the methodological approach or the tools. The tools were completed without difficulty, adding support to the validity of the tools. Little modifications were made, e.g., rephrasing and rearrangements of some sentences. Mothers involved in the pilot study were excluded from the main study sample.

\section{Statistical Analysis}

The collected data were coded, tabulated, and analyzed using the Statistical Package for Social Science (SPSS 20.0). Descriptive data were expressed as mean and standard deviation. Qualitative data were expressed as frequency and percentage. Fisher test was used to detect the relation between mothers' knowledge based on their selected personal variables. Comparisons of means were performed using a paired-sample t-test. Level of significance at $\mathrm{p}<0.05$, 0.001 were used as the cut of value for statistical significance. 


\section{Results:}

Table (1): Personal Data of Studied Mothers in Percentage Distribution $(n=35)$.

\begin{tabular}{|l|l|l|}
\hline Personal data & No & $\%$ \\
\hline Age / years & 16 & 45.7 \\
\hline $35-<40$ & 7 & 20.0 \\
\hline $40-<45$ & 8 & 22.9 \\
\hline $45-<50$ & 4 & 11.4 \\
\hline $50-<55$ & $42.5 \pm 5.4$ years \\
\hline Mean \pm SD & 35 & 100 \\
\hline The degree of closeness to the mother: \\
\hline Mothers & 35 & \\
\hline Level of education & 10 & 28.6 \\
\hline Not read and write & 6 & 17.1 \\
\hline Read and write & 18 & 51.4 \\
\hline Basic education & 1 & 2.9 \\
\hline Secondary education & 2 & 5.7 \\
\hline Place of residence & 33 & 94.3 \\
\hline Urban area & 33 \\
\hline Rural area &
\end{tabular}

Regarding mothers' personal data, the current study results revealed that more than two fifth (45.7\%) of the studied mothers were $35-<40$ years old, and the mean of their age was $42.5 \pm 5.4$ years. All $(100 \%)$ of mothers who participated in the current study were mothers. More than half (51.4\%) of them have basic education, and $94.3 \%$ lived in rural areas (Table 1$)$.

Table (2): Personal Characteristics of Studied Children Having Cancer and Undergoing Chemotherapy in Percentage Distribution $(\mathbf{n}=35)$.

\begin{tabular}{|l|l|l|}
\hline Personal data & No & \% \\
\hline Age of the child/ years: & 12 & 34.3 \\
\hline $1-<5$ & 14 & 40.0 \\
\hline $5-<10$ & 9 & 25.7 \\
\hline $10-15$ & $3.4 \pm 4.0$ years \\
\hline Mean \pm SD & \multicolumn{1}{|l|}{} \\
\hline Child' gender: & 14 & 40.0 \\
\hline Male & 21 & 60.0 \\
\hline Female & 11 & 31.4 \\
\hline The rank of the child within the family: \\
\hline First & 11 & 17.2 \\
\hline Second & 6 & 51.4 \\
\hline Third and more & 18 & \\
\hline
\end{tabular}

Table (2) clarified that $40 \%$ of the studied children were $5-<10$ years old, their mean age was $3.4 \pm 4.0$ years, and $60 \%$ were female. More than half $(51.4 \%)$ of the children were ranked as the third and more within their families.

Table (3): Current Medical History of the Studied Children in Percentage Distribution (n=35).

\begin{tabular}{|l|l|l|}
\hline Current medical history & No & $\%$ \\
\hline Type of cancer & 14 & 40.0 \\
\hline Leukemia & 4 & 11.4 \\
\hline Nervous system cancer & 7 & 20.0 \\
\hline Lymphoma & 1 & 2.9 \\
\hline Adrenal cancer & 6 & 17.1 \\
\hline Kidney cancer & 3 & 8.6 \\
\hline Bone cancer & 15 & 42.9 \\
\hline How long has cancer been discovered? \\
\hline Within the past week & 20 & 57.1 \\
\hline Within the last two weeks & 5 & 14.3 \\
\hline Cancer-related surgery performed & 30 & 85.7 \\
\hline Yes & 8 & 22.9 \\
\hline No & 7 & 20.0 \\
\hline Symptoms & 2 & 5.7 \\
\hline Fever & 2 & 5.7 \\
\hline Enlarged lymph nodes & 1 & 2.9 \\
\hline Headache or vomiting & 5 & 14.3 \\
\hline Bone or joint pain & 1 & 2.9 \\
\hline Abdominal pain & 3 & 8.6 \\
\hline Fever and enlarged nodes & 4 & 11.4 \\
\hline Fever and pallor & 1 & 2.9 \\
\hline Fever, pallor, and pain & 1 & 2.9 \\
\hline Enlarged nodes and bleeding & \multicolumn{2}{|l}{} \\
\hline Chest pain & \multicolumn{2}{|l|}{} \\
\hline Legs edema & \multicolumn{1}{|l|}{} \\
\hline \multicolumn{2}{|l|}{} \\
\hline
\end{tabular}


Table (3) showed that $40 \% \%$ of children have Leukemia, followed by Lymphoma, and $57.1 \%$ were discovered within the last two weeks. The majority $(85.7 \%)$ of the children didn't have any cancer-related surgery performed on them. Fever and enlarged lymph nodes were the main symptoms experienced by children in the current study $(22.9 \% \& 20 \%$ respectively).

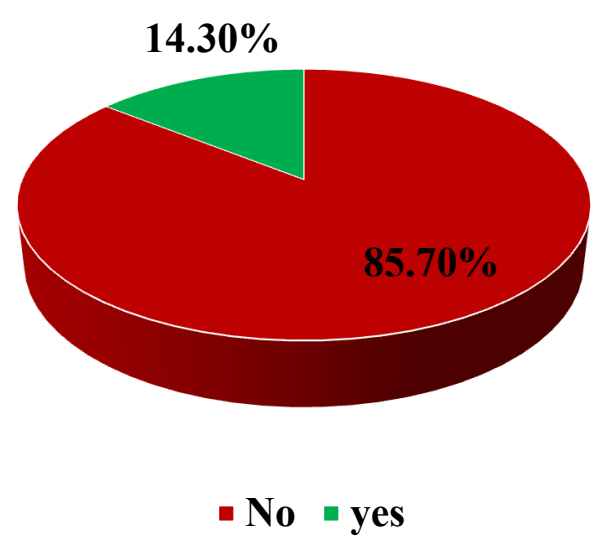

Figure (1): Number and percentage distribution of Mothers who Received Information About Childhood Cancer and Chemotherapy ( $N=35)$.

Regarding mothers' knowledge, Figure (1): proved that the majority (85.7\%) of the mothers hadn't been given any knowledge about childhood cancer and chemotherapy.

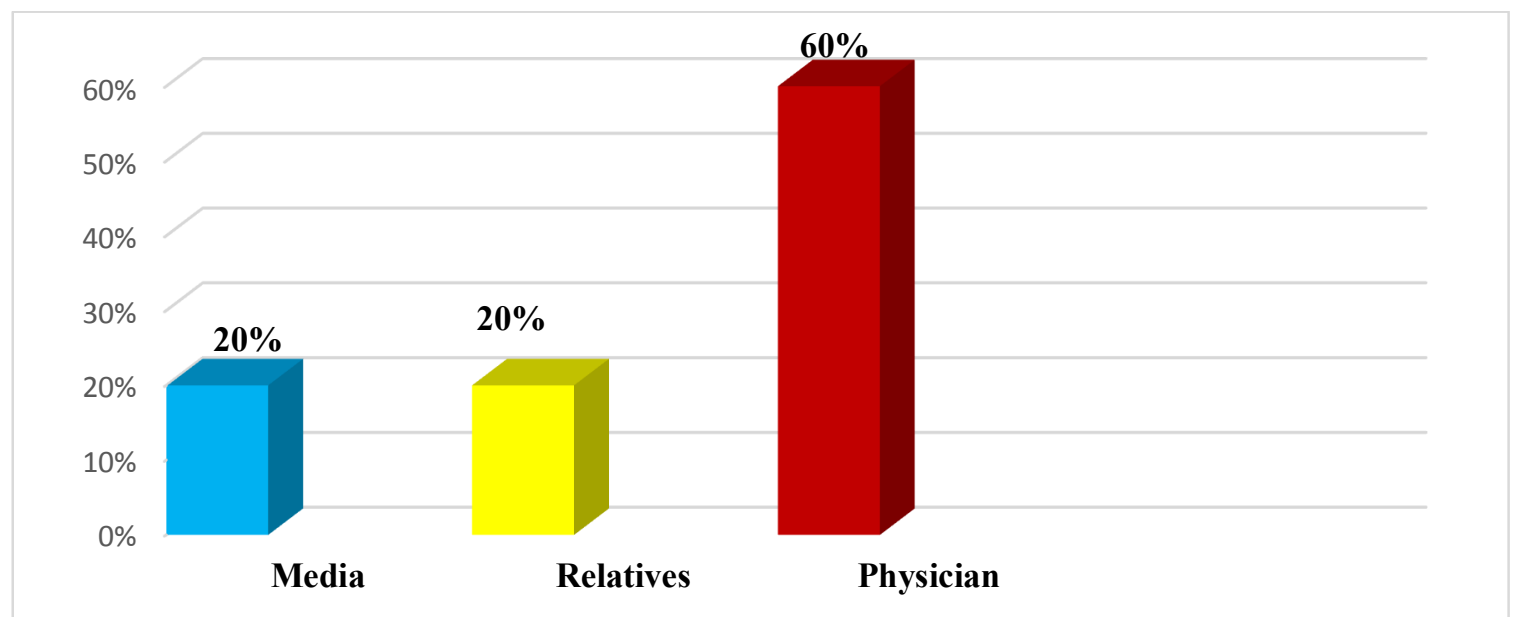

Figure (2): Sources of Mothers Been Given Knowledge About Childhood Cancer and Chemotherapy in Percentage Distribution (N=35).

Regarding the sources of knowledge given to mothers about childhood cancer and chemotherapy, figure (2) proved that the mothers' highest percentage $(60 \%)$ received their knowledge about childhood cancer and chemotherapy from physicians.

Table (4): Mothers' Knowledge about Childhood Cancer and chemotherapy in Percentage Distribution (n=35).

\begin{tabular}{|c|c|c|c|c|c|c|}
\hline \multirow[t]{2}{*}{ Mothers' knowledge } & \multicolumn{2}{|c|}{ Complete } & \multicolumn{2}{|c|}{ Incomplete } & \multicolumn{2}{|c|}{ Don't know } \\
\hline & No & $\%$ & No & $\%$ & No & $\%$ \\
\hline Definition of cancer & 0 & 0 & 0 & 0 & 35 & 100 \\
\hline The most common types of cancer in children & 0 & 0 & 4 & 11.4 & 31 & 88.6 \\
\hline The common symptoms of childhood cancer & 0 & 0 & 1 & 2.9 & 34 & 97.1 \\
\hline Predisposing factors of childhood cancer & 0 & 0 & 0 & 0 & 35 & 100 \\
\hline The different treatment methods for childhood cancer: & 0 & 0 & 0 & 0 & 35 & 100 \\
\hline Definition of chemotherapy & 0 & 0 & 3 & 8.6 & 32 & 91.4 \\
\hline Uses of chemotherapy & 0 & 0 & 0 & 0 & 35 & 100 \\
\hline The different ways to give chemotherapy & 0 & 0 & 0 & 0 & 35 & 100 \\
\hline All cancers treated with one type of chemotherapy & 0 & 0 & 0 & 0 & 35 & 100 \\
\hline Total mean score of mothers' knowledge & \multicolumn{6}{|c|}{$10.4 \pm 4$} \\
\hline
\end{tabular}

Table (4) highlighted that all (100\%) of the mothers don't know the definition of cancer, predisposing factors of childhood cancer, treatment methods, and uses of chemotherapy. The majority $(88.6 \%, 97.1 \% \& 91.4 \%$, respectively) of the mothers don't know the most common types of cancer in children and its symptoms and cannot define chemotherapy. The total mean score of the mothers' knowledge was $10.4 \pm 4$. 
Minia Scientific Nursing Journal (Print - ISSN 2537-012X) (Online - ISSN 2785-9797) Vol. (8) No. (1) December 2020

Table (5): Mothers' Performance Regarding Chemotherapy in the Pre-test, Post-test, and Follow-up (n= 35).

\begin{tabular}{|c|c|c|c|c|c|c|}
\hline \multirow[t]{2}{*}{ Mothers' Performance } & \multicolumn{2}{|c|}{ Complete } & \multicolumn{2}{|c|}{ Incomplete } & \multicolumn{2}{|c|}{ Don't know } \\
\hline & No & $\%$ & No & $\%$ & No & $\%$ \\
\hline Side effects on the bone marrow & 0 & 0 & 4 & 11.4 & 31 & 88.6 \\
\hline Side effects on the digestive system & 0 & 0 & 4 & 11.4 & 31 & 88.6 \\
\hline Side effects on skin and hair & 0 & 0 & 4 & 11.4 & 31 & 88.6 \\
\hline Side effects on the respiratory system & 0 & 0 & 0 & 0 & 35 & 100 \\
\hline Protect the child from infection & 0 & 0 & 0 & 0 & 35 & 100 \\
\hline Conditions that need contact with the physician immediately & 0 & 0 & 0 & 0 & 35 & 100 \\
\hline Mothers' performance when the child exposed to bleeding & 0 & 0 & 0 & 0 & 35 & 100 \\
\hline Mothers' performance when the child exposed to anorexia & 0 & 0 & 0 & 0 & 35 & 100 \\
\hline Mothers' performance when the child exposed to vomiting & 0 & 0 & 0 & 0 & 35 & 100 \\
\hline Mothers' performance when the child suffering from pain & 0 & 0 & 2 & 5.7 & 33 & 94.3 \\
\hline Management of hair loss & 0 & 0 & 1 & 2.9 & 34 & 97.1 \\
\hline Mothers' performance when the child exposed to diarrhea & 0 & 0 & 0 & 0 & 35 & 100 \\
\hline Mothers' performance when the child exposed to mouth and throat problems & 0 & 0 & 0 & 0 & 35 & 100 \\
\hline Total mean score of mothers' performance & & & & $8 \pm 0.7$ & & \\
\hline
\end{tabular}

In relation to the mothers' performance regarding childhood cancer and chemotherapy, table (5) revealed that equal percentages $(88.6 \%)$ of the mothers don't know the side effects of chemotherapy on bone marrow, digestive system, skin, and hair and respiratory system. All (100\%) of the mothers don't know what to do in the case of their children exposed to infection, bleeding, anorexia, vomiting, pain, hair loss, and mouth and throat problems. The total mean score of the mothers' knowledge was $4.8 \pm 0.7$.

Table (6): Mothers' Level of Knowledge and Performance Toward Childhood Cancer and Chemotherapy (n=35).

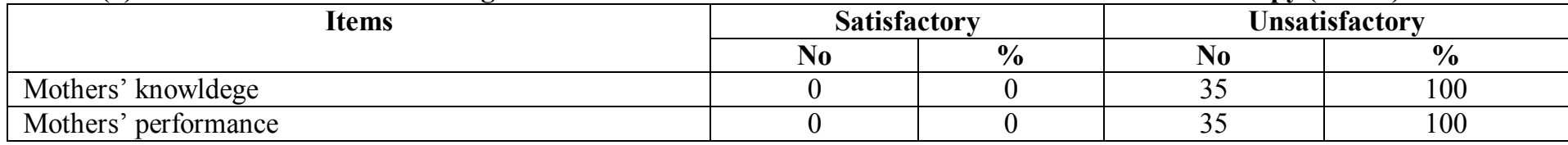

Table (6) demonstrated that all (100) of the mothers had an unsatisfactory level of knowledge and performance regarding childhood cancer and chemotherapy.

Table (7): Relations Between the Total Mean Score of Mothers' Knowledge Regarding Cancer and Chemotherapy and Their Personal Data $(\mathbf{n}=\mathbf{3 5})$.

\begin{tabular}{|c|c|c|c|c|}
\hline Personal data & No. & Mean \pm SD & \multicolumn{2}{|c|}{ Test of significance } \\
\hline Age / years & & & $\mathrm{t} / \mathrm{F}$ test & $\mathrm{P}$ - value \\
\hline $35-<40$ & 16 & $6.3 \pm .4$ & \multirow{4}{*}{1.148} & \multirow{4}{*}{$\begin{array}{l}.345 \\
\text { NS }\end{array}$} \\
\hline $40-<45$ & 7 & $6.1 \pm .4$ & & \\
\hline $45-<50$ & 8 & $6.0 \pm .0$ & & \\
\hline $50-<55$ & 4 & $6.0 \pm .0$ & & \\
\hline \multicolumn{5}{|l|}{ Level of education } \\
\hline Not read and write & 10 & $12.0 \pm .0$ & \multirow{4}{*}{1.930} & \multirow{4}{*}{$\begin{array}{l}.145 \\
\mathrm{NS}\end{array}$} \\
\hline Read and write & 6 & $8.0 \pm .0$ & & \\
\hline Basic education & 18 & $6.3 \pm .5$ & & \\
\hline Secondary education & 1 & $6.0 \pm .5$ & & \\
\hline \multicolumn{5}{|c|}{ The social status of the mother } \\
\hline Married & 34 & $12.1 \pm .4$ & \multirow[t]{2}{*}{.163} & \multirow{2}{*}{$\begin{array}{l}.689 \\
\text { NS }\end{array}$} \\
\hline Divorced & 1 & $6.0 \pm .0$ & & \\
\hline \multicolumn{5}{|l|}{ Place of residence } \\
\hline Urban area & 2 & $6.0 \pm .0$ & \multirow[t]{2}{*}{.337} & .566 \\
\hline Rural area & 33 & $12.2 \pm .4$ & & NS \\
\hline \multicolumn{5}{|l|}{ Occupation } \\
\hline Works outside the home & 1 & $6.0 \pm .0$ & \multirow[t]{2}{*}{.163} & \multirow{2}{*}{$\begin{array}{l}.689 \\
\text { NS }\end{array}$} \\
\hline House wife & 34 & $12.2 \pm .4$ & & \\
\hline
\end{tabular}

$\mathrm{NS}=$ Not statistically significant differences $* *$ Highly statistically significant differences

Regarding the relations between the total mean score of mothers' knowledge regarding childhood cancer and chemotherapy and their personal data, table (7) illustrated that there were no statistically significant relations between the total mean scores of mothers' knowledge regarding childhood cancer and chemotherapy and their age, level of education, social status, place of residence, occupation, and family type $(\mathrm{p}=>0.05)$.

Table (8): Relations between the total mean score of the mothers' performance regarding cancer and chemotherapy and their personal data $(\mathbf{n}=35)$.

\begin{tabular}{|c|c|c|c|c|}
\hline Personal data & No. & Mean \pm SD & \multicolumn{2}{|c|}{ Test of significance } \\
\hline Age / years & & & $t / F$ test & \\
\hline $35-<40$ & 16 & $5 \pm .9$ & \multirow{4}{*}{.518} & \multirow{4}{*}{$\begin{array}{l}.673 \\
\text { NS }\end{array}$} \\
\hline $40-<45$ & 7 & $4.6 \pm .8$ & & \\
\hline $45-<50$ & 8 & $4.8 \pm .5$ & & \\
\hline $50-<55$ & 4 & $4.0 \pm .0$ & & \\
\hline Level of education & & & & \\
\hline
\end{tabular}




\begin{tabular}{|c|c|c|c|c|}
\hline Personal data & No. & Mean \pm SD & & significance \\
\hline Not read and write & 10 & $4.0 \pm .0$ & \multirow{4}{*}{3.462} & \multirow{4}{*}{$.028 *$} \\
\hline Read and write & 6 & $4.0 \pm .0$ & & \\
\hline Basic education & 18 & $5.4 \pm .9$ & & \\
\hline Secondary education & 1 & $4.0 \pm .0$ & & \\
\hline \multicolumn{5}{|c|}{ The social status of the mother } \\
\hline Married & 34 & $4.8 \pm .7$ & \multirow[t]{2}{*}{.260} & \multirow{2}{*}{$\begin{array}{l}.614 \\
\text { NS } \\
\end{array}$} \\
\hline Divorced & 1 & $4.0 \pm .0$ & & \\
\hline \multicolumn{5}{|l|}{ Place of residence } \\
\hline Urban area & 2 & $4.0 \pm .0$ & \multirow[t]{2}{*}{.540} & \multirow{2}{*}{$\begin{array}{l}.468 \\
\text { NS }\end{array}$} \\
\hline Rural area & 33 & $4.8 \pm .8$ & & \\
\hline \multicolumn{5}{|l|}{ Occupation } \\
\hline Works outside the home & 1 & $4.0 \pm .0$ & \multirow[t]{2}{*}{.163} & \multirow{2}{*}{$\begin{array}{l}.689 \\
\text { NS }\end{array}$} \\
\hline Housewife & 34 & $4.8 \pm .8$ & & \\
\hline \multicolumn{5}{|l|}{ Family type } \\
\hline Extended & 25 & $4.4 \pm .5$ & \multirow[t]{2}{*}{5.440} & \multirow[t]{2}{*}{$.026^{*}$} \\
\hline Nuclear & 10 & $5.6 \pm 1.1$ & & \\
\hline
\end{tabular}

$\mathrm{NS}=$ Not statistically significant differences $*=$ Statistical significant differences

** Highly statistically significant differences

Regarding the relations between the total mean scores of mothers' performance regarding childhood cancer and chemotherapy and their personal data, table (8) illustrated that there were statistically significant relations between the total mean score of mothers' performance and their level of education and type of family $(p=<0.05)$. There were no statistically significant relations between the total mean scores of mothers' performance regarding childhood cancer and chemotherapy and their age, social status, place of residence, and occupation $(\mathrm{p}=>0.05)$.

\section{Discussion}

The current study results assured that the highest percentage of studied mothers were $35-<40$ years old, and the mean of their age was $42.5 \pm 5.4$ years. All of the mothers who participated in the current study were mothers. These results supported a study done by Hamad and Shaker (2019) to assess the coping strategies among 54 mothers of children with acute leukemia in Iraq. The study results proved that mothers' mean age was $36.53 \pm 7.53$ years, and the majority of chief mothers $(87 \%)$ were mothers.

The current study results evident that more than half of the mothers had basic education, and their minority did not read and write. The result reflected that higher literacy rates among Egyptian mothers, especially in upper Egypt. On the same line, the Egypt Demographics Profile (2017) assured that females' literacy rate was $65.5 \%$ compared to $63.5 \%$ in 2016. Accordingly, efforts of governmental and nongovernmental organizations should continue to focus on female education because low levels of literacy can hinder the economic development of a country in the current rapidly changing, technology-driven world, this; of course, will reflect positively on the health care system as a whole as well as care provided for the sick child.

In a descriptive-correlational study carried out by Khademi et al. (2019) to assess the caring power of 196 mothers who have a child with cancer and its predictors, the study results concluded that the average age of the mothers was 34.53 years. Similarly, in an Egyptian study conducted by Hassan and Ibrahim (2018) to determine the effect of supportive nursing intervention on the burden and coping strategies of 60 mothers of children with cancer. The results showed that more than ninety percent of primary caregivers were mothers in both groups, and $65 \%$ of the total mothers' ages ranged from 30 to $>35$ years. More than one third $(38.3 \%)$ of studied mothers have had a technical education, and high education represented thirty-five percent. Ninety percent of mothers of studied cancer children were housewives.

In an Egyptian study held by Taha, Mohamed, Mahmoud, and Khaled (2019) to evaluate the effect of nursing instructions on knowledge and reported-practice of 50

P a g e | 71 mothers having children with leukemia undergoing chemotherapy. The study results summarized that the highest percentage of mothers' ages ranged from 30 to 35 years and had basic and secondary school education. The vast majority of mothers were married and housewives.

The current study results revealed that the majority of mothers came from rural areas. This result could be related to the Minia Oncology Center serving children with various types of cancers in the Minia governorate and surrounding rural and semi-urban areas. In the same context, the United Nations Educational, Scientific, and Cultural Organization [UNESCO] (2017) documented that the rural population was $57 \%$ of the total population worldwide. In the same line, Egypt Demographics Profile (2020) reported that the rural community was $57 \%$ of the total residents, and the rate of urbanization was $1.68 \%$ annual rate of change.

Concerning children's characteristics, the current study results clarified that the highest percentage of the studied children were $5-<10$ years old, their mean age was $3.4 \pm 4.0$ years, and nearly two-thirds of them were females. More than half of the children were ranked as the third and more within their families. Forty percent of the studied children were diagnosed with leukemia. These results were in accordance with a study done by Hamad and Shaker (2019), who found that more than half $(52 \%)$ of the children were females, and the majority $(88.9 \%)$ of them were diagnosed with leukemia. On the same perspective, Motlagh, MirzaeiAlavijeh, and Hosseini (2019) found that the mean age of children with cancer was 5.57 years, $47.1 \%$ of the children were female, and $52.9 \%$ were male.

Expanding recent literature by the American Cancer Society (2020) also demonstrated that leukemia is the most significant common in early childhood, peaking between 2 and 4 years of age. There are numerous leukemia types, including acute lymphocytic leukemia (ALL) and acute myeloid leukemia (AML), which start in the bone marrow or blood. Leukemia could cause bone and joint pain, fatigue, weakness, pale skin, bruising, fever, weight loss, and enlarged lymph nodes.

Recently, the American Cancer Society (2020) documented that numerous signs and symptoms of childhood

El Shaima G., et al 
cancer. Common symptoms include fatigue, pale skin, infections and fever, easy bleeding or bruising, shortness of breath, bone or joint pain, loss of appetite, loss of weight, abdominal distention and sometimes headaches, seizures, balance problems, and vomiting. The findings of the current study were in accordance with the above-mentioned empirical evidence and proved that the highest percentage of studied children complained from fever, enlarged lymph nodes, and bleeding.

The current study results proved that the majority of the mothers did not give any knowledge about childhood cancer and chemotherapy. These results could be rationalized as the mothers were not informed about childhood cancer and chemotherapy. These results also showed the urgent need to implement teaching sessions for mothers about that issue for the provision of a safe child's life in all pediatric oncology health care settings.

Concerning mothers' knowledge about childhood cancer and chemotherapy, the current study results revealed that the highest percentages of mothers didn't know or had incomplete knowledge about cancer and its causes and symptoms. Also, mothers had incomplete knowledge related to chemotherapy and its side effects The overall level of mothers' knowledge about childhood cancer and chemotherapy was unsatisfactory. These results indicate the mothers' need for knowledge and instructions about childhood cancer and chemotherapy. The inadequate mothers' knowledge may exacerbate familial stress and negatively affect their children's clinical outcomes. Adverse events associated with insufficient education may include unexpected medical problems.

As emphasized by Hockenberry and Wilson (2019), nurses working with children who have cancer have a substantial supporting role in helping the mothers understand the various therapies, preventing or managing expected side effects or toxicities, and observing for late effects of treatment. Education is a constant feature of the nursing role, especially in new treatments, clinical trials, and home care. Pediatric nurses are influential in helping families avoid seeking unproven and potentially unsafe traditional management methods.

These results were consistent with Taha et al. (2019); they found that most mothers of children with leukemia had wrong or incomplete knowledge related to etiology, symptoms, and childhood cancer treatment. Besides, the vast majority of the mothers had incomplete items of reported-practice regarding their children's care before, during, and after chemotherapy sessions. Similarly, Mahmoud and Abd Elaziz (2015) evaluated the effect of a psycho-educational training program for 60 parents who have a child with cancer blood on their experience and psychological well-being. The study results summarized that most of the pre-test parents had insufficient knowledge related to the definition, causes, symptoms, and treatment modalities of childhood cancer.

Regionally in Iraq, in a previous study carried out by Obaid, Ajil, and Al-Ganmi (2014) to assess knowledge about chemotherapy for leukemic child and their 70 mothers and to find out the relationship between the mother's knowledge and the demographic characteristics for mothers, child and child's illness. The study results demonstrated a knowledge deficit of mothers in some aspects related to chemotherapy treatment. Most mothers who have a child with cancer and receiving chemotherapy have a moderate knowledge level.

The newest recommendations indicate that it is crucial to ensure that mothers understand several fundamental concepts elaborate in caring for a child with cancer within the first days after diagnosis and after discharge following the initial hospital admission, so parents know how and when to seek care at the hospital (Jackson, Liang, Frydenberg, Higgins, \& Murphy, 2016). On the contrary, the current study results demonstrated that all mothers had an unsatisfactory level of knowledge regarding childhood cancer and chemotherapy.

On the same line, Saeed, hamzah, and Nitavid (2019) studied the effectiveness of a structured teaching program on enhancing mothers' knowledge about childcare for children with cancer blood in India. The study results revealed that $38.53 \%$ of the mothers had inadequate knowledge, and $34.86 \%$ of mothers had moderate knowledge. The same results were attained by Samaan (2020), who assessed mothers' care for their children with leukemia undergoing chemotherapy concluded that $67.5 \%$ of the mothers had low total knowledge scores regarding leukemia and chemotherapy. Moreover, $24.4 \%$ of the mothers had a fair total score of knowledge. Meanwhile, only $8.1 \%$ of them had a good total score of knowledge.

Concerning mothers' performance provided for their children with cancer, the current study results highlighted that the majority of the mothers were not able to provide care for their children. Mothers reported incomplete care for their children as regards the side effects of chemotherapy. The highest percentages were not oriented by the precautions taken to protect the child at home after a chemotherapy session. Inappropriately, all mothers had an unsatisfactory performance level regarding the care of their children with cancer and undergoing chemotherapy. These results could have a negative impact on their ability to provide proper care for their children. The overall level of the mothers' performance was unsatisfactory. These results could have a negative impact on their ability to provide adequate care for their children.

Similarly, Taha et al. (2019) confirmed that $98 \%$ and $100 \%$ respectively of the mothers don't know the care should be provided for their children before and during chemotherapy. All the mothers who participated in their study had insufficient reported-practice before receiving the nursing instructions.

The current study results clarified that there were no statistically significant relationships between the total mean scores of mothers' knowledge and total mothers' practice regarding childhood cancer and chemotherapy and their age, level of education, social status, place of residence, their children's age, and gender and the child's rank in the family $(p=>0.05)$. So, it could be concluded that personal variables have no impact on the mothers' knowledge and performance.

These results were supported by Kaur, Chanu, and Sorte (2017), who assessed the effectiveness of a structured educational program on knowledge regarding home management of side effects of chemotherapy among parents in India. The results illustrated no statistically significant association between knowledge score and their selected demographic variable in terms of age of parents, level of education, age of the child, gender, and child diagnosis. These results are contradicted with Taha et al. (2019), they found that there were highly statistically significant positive 
correlations between mothers' total mean score of knowledge and reported practice and their level of education. These results also contradicted the study by Priya et al. (2019); they found a significant association between knowledge with the child's age and the number of children. In practice, an association was found between the gender of the child and the educational status of the mother.

\section{Conclusion}

The current study results concluded that there was an obvious lacking in knowledge and performance of the mothers having children with cancer undergoing chemotherapy. The overall level of mothers' knowledge and performance was unsatisfactory. There were no statistically significant relationships between the total mean scores of mothers' knowledge and performance regarding childhood cancer and chemotherapy and their age, level of education, social status, place of residence, occupation, children's age, gender, and child's rank in the family.

Recommendations: The study recommended that;

- Development and application of an educational program for mothers in pediatric oncology units are mandatory to provide a framework for mothers' role for their children with cancer.

- The pediatric oncology health care institutions should establish a committee responsible for teaching children newly diagnosed with cancer and their mothers about the disease and its management modalities.

- Healthcare professionals, including pediatric oncology nurses, should consider developing informational booklets for mothers to refer to specific cancer varieties and treatment protocols.

- There should be arrangements for social programs like mother's meetings etc. by various organizations to increase public awareness about childhood cancer.

- This study's replication is warranted; this would enhance opportunities to generalize the findings to other types of pediatric oncological disorders and different pediatric oncology clinical settings.

\section{Acknowledgment:}

The authors are thankful for the great help and cooperation received from the mothers of children with cancer who participated in the current study. Many thanks to all staff members of the Oncology Center, Minia Governorate, to support and cooperate to accomplish this study.

\section{References}

(1) American Cancer Society (2020). Key Statistics for Childhood Cancers, available at https://www.cancer.org/research/cancerfacts-statistics/all-cancer-facts-figures/cancer-facts-figures2020.html

(2) Ameringer, s., Macpherson, N. \& Jibb, L. (2020). Symptom Science in Pediatric Oncology, Pediatric Oncology Nursing, Defining Care Through Science pp:79-85, https://doi.org/10.1007/978-3-030-25804-7

(3) Attar, R., Zagade, T., \& Shinde, M. (2020). An efficacy of structured teaching program on knowledge of caregivers of chronic ill cancer patients regarding oral care. International Journal of Advanced Science and Technology, 29(8s), 3214-3221.

(4) Egypt Demographics Profile (2017). Available at www.indexmundi.com/egypt/ demographics_profile. Accessed on $26 / 9 / 2020$
(5) Egypt Demographics Profile (2020). Available at www.indexmundi.com/egypt/ demographics_profile. Accessed on 26/9/2020.

(6) Hamad, S., \& Shaker, N. (2019). Coping Strategies among Caregivers of Children with Acute Leukemia at Nanakali Hospital in Erbil City. Erbil Journal of Nursing and Midwifery, 2(2), 155 162. https://doi.org/10.15218/ejnm.2019.19

(7) Hassan, G.A., \& Ibrahim, H.S. (2018). The effect of supportive nursing intervention on the burden and coping strategies of caregivers of children with cancer. Journal of Nursing Education and Practice.;8(7):125. Available from: https://doi.org/10.5430/jnep.v8n7p125

(8) Haugen, M., Zupanec, S., \& Landier, W. (2020) Improving Care Through Patient and Family Education in Pediatric Oncology. In: Hinds P., Linder L. (eds) Pediatric Oncology Nursing. Pediatric Oncology. Springer, Cham. https://doi.org/10.1007/978-3-03025804-7_6

(9) Hockenberry, M. J., \& Wilson, D. (2019). Wong's Nursing Care of Infants and Children11th ed, Elsevier Health Sciences. London.pp 405-408.

(10) Howard, S.C., Zaidi, A., Cao, X., Weil, O., Bey, P., Patte, C........\& Lacheteau, G. (2018). The My Child Matters program: effect of public-private partnerships on pediatric cancer care in low-income and middle-income countries. Lancet Oncology ;19(5): e252-e266.

(11) Jackson, A.C., Liang, R.P., Frydenberg, E., Higgins, R.O., \& Murphy, B.M. (2016). Parent education program for special health care needs children: a systematic review. Journal of Clinical Nursing. 2016;25(11-12):1528-1547. doi:10.1111/jocn.13178

(12) Kamel, H., Baraka, H., Khalid, H., \& Ibrahim, A. (2009). Egypt National Cancer Registry, El-Minia profile.

(13) Kaur, R., Chanu, S.E., \& Sorte, D.Y. (2017). A Study to Assess the Effectiveness of Structured Teaching Program on Knowledge Regarding "Home Management of Side Effects of Chemotherapy" among Parents. Pediatric Therapeutics 7: 333. doi:10.4172/21610665.1000333

(14) Khademi, F., Rassouli, M., Khanali, L., Heidarzadeh, M., Shirinabadi, M., \& Borumandni, N. (2019). Caring power of mothers who have a child with cancer and its predictors. Iranian Journal of Pediatric Hematology and Oncology; 9(3):173-183.

(15) Mahmoud, S., \& Elaziz, N. A. A. (2015). Effect of PsychoEducational Training Program for Parent's Having Child with Leukemia on Their Experience and Psychological Wellbeing. Journal of Education and Practice, 6(12), 13- 29.

(16) Marcdante, K., \& kliegman, R. (2019). Nelson Essentials of Pediatrics, Principles of Cancer Treatment, 8th ed, Philadelphia, Pp: 1538

(17) Motlagh, M.E., Mirzaei-Alavijeh ,M., \& Hosseini, S.N. (2019). Care Burden in Parents of Children with Leukemia: A CrossSectional Study in the West of Iran. International Journal of Pediatrics; 7(6): 9541-9548.

(18) National Cancer Control Plan of Egypt 2016-2020

(19) Newman, A., Crane, S., Spruit, J., Alharrasi, S., \& Bell, C. (2020). Palliative Care in Pediatric Oncology, Pediatric Oncology Nursing, Defining Care Through Science pp: 191-196, https://doi.org/10.1007/978-3-030-25804-7

(20) Obaid, K., Ajil, Z. \& Al-Ganmi, A. (2014). Mothers' knowledge concerning leukemic children undergoing chemotherapy: treatment in oncology units at Baghdad city. Asian Academic Research Journal of Multidisciplinary. 2014:1:527 - 542.

(21) Priya, V., David, A., \& Geetha, D. (2019). Effectiveness of structured teaching program on knowledge and practice regarding care of children with leukemia among mothers. Journal of Experimental Therapeutics and Oncology. 2019;13(2):147-154.

(22) Saeed, N.A., Hamzah, I.H., \& Nitavid, A. (2019). Structured teaching program enhances the knowledge of mothers to take care of children with leukemia. Journal of Public Health, 1-6.

(23) Samaan. A. (2020). Care Provided by Mothers for their Children with leukemia Undergoing Chemotherapy. Asian Academic Research Journal of Multidisciplinary 1(24):527 - 542

(24) Siegel, R.L., Miller, K.D., \& Jemal, A. (2019). Cancer statistics. Journal of Clinical Cancer. ;69(1):7-34 https://doi.org/10.3322/caac.21551.

(25) Singaraju, M., Palaian, S., Shankar, P. R., \& Shrestha, S. (2020). Safety profile and toxicity amelioration strategies of common adverse effects associated with anticancer medications. Journal of 
Pharmaceutical Research International, 32(11), 18-30. https://doi.org/10.9734/jpri/2020/v32i1130499

(26) Soliman, R., Elhaddad, A., Oke, J., Eweida, W., \& Sidhom, I. (2019). Childhood cancer health outcomes in Egypt: ten-year realworld evidence from children's cancer hospital 57357- Egypt (CCHE) and comparison with results from England, VL - 24, JO British Medical Journal Evidence-Based Medicine, DOI 10.1136/bmjeb-EBMLive.27

(27) Taha, M., Mohamed, S., Mahmoud, N, \& Khalid W. (2019). Effect of Nursing Instructions on Knowledge and Practice of Mothers Having Children with Leukemia Undergoing Chemotherapy. The Medical Journal of Cairo University, 87(June), 2447-2458. doi: $10.21608 / \mathrm{mjcu} .2019 .54853$
(28) Tomlinson, D., Yuan, C., Cheng, L., \& Hinds, P. (2020). PatientReported Outcomes in Pediatric Oncology: The Voice of the Child, Pediatric Oncology Nursing, Defining Care Through Science pp:107-109, https://doi.org/10.1007/978-3-030-25804-7

(29) United Nations Educational, Scientific, and Cultural Organization (UNESCO) (2017). Education in rural community. Available at www.un.org.Accessed on 1/9/2020.

(30) Valizadeh, L., Zamanzadeh, V., Ghahremanian, A., Musavi, S., Akbarbegloo, M., \& Chou, F.Y. (2020). Experience of adolescent survivors of childhood cancer about self-care needs: a content analysis. Asia Pacific Journal of Oncology Nursing; 7:72-80.

(31) World Health Organization (2018). Cancer in children. Available at https://www.who.int/news-room/fact-sheets/detail/cancer-inchildren. Accessed on 1/5/2020. 